\title{
STUDI SANITASI BARBERSHOP (TEMPAT PANGKAS RAMBUT) DI WILAYAH KERJA PUSKESMAS II PURWOKERTO UTARA TAHUN 2015
}

\author{
Dwiana Widyawati' ${ }^{1)}$, Mawaddah'2) \\ Jurusan Kesehatan Lingkungan, Politeknik Kesehatan Kemenkes Semarang, \\ Jl.Raya Baturaden KM 12 Purwokerto, Indonesia
}

\begin{abstract}
Abstrak
Sanitasi adalah suatu cara untuk mencegah berjangkitnya suatu penyakit menular dengan jalan memutuskan mata rantai dari sumber. Sanitasi merupakan usaha kesehatan masyarakat yang menitik beratkan pada penguasaan terhadap berbagai faktor lingkungan yang mempengaruhi. Barbershopadalah suatu tempat dimana umum dapat memotong rambutnya dengan dipungut biaya. Tujuan penelitian ini adalah ingin mengetahui keadaan sanitasi Barbershop yang ada di Wilayah Kerja Puskesmas II Purwokerto Utara tahun 2015. Jenis penelitian yang digunakan adalah jenis penelitian deskriptif. Penelitian deskriptif adalah sebuah metode penelitian yang dilakukan dengan tujuan untuk membuat gambaran atau deskripsi tentang suatu keadaan secara obyektif. Hasil penelitian yang telah dilakukan pada barbershop di wilayah kerja Puskesmas II Purwokerto Utara yang berjumlah enam tempat hasilnya masuk dalam kategori Cukup Baik dengan nilai tertinggi pada tempat pangkas rambut $F$ dengan nilai $79 \%$ nilai terendah pada tempat pangkas rambut D yaitu 57\% dan rata - rata nilai pada masing - masing tempat pangkas rambut yaitu 66\%. Simpulan penelitian ini adalah Keadaan sanitasi Barbershop pada enam tempat yang ada di wilayah kerja Puskesmas II Purwokerto Utara mendapat kategori Cukup Baik dengan nilai rata - rata $66 \%$.
\end{abstract}

Kata kunci : Sanitasi, Sanitasi Tempat-tempat umum

\begin{abstract}
The Study Of Barbershop Sanitation In The Area Of Puskesmas II Purwokerto Utara In 2015. Sanitation is a way to prevent an outbreak of infectious disease with roads break the chain of sources. Sanitation is a public health effort that focuses on the mastery of the various environmental factors that influence. Barbershop is a place where the public can cut hair for a fee. The purpose of this research is to know the state of sanitation Barbershop in Puskesmas II North Purwokerto year of 2015. This type of research is descriptive research. Descriptive research is a method of research conducted with the aim to create a picture or a description of a situation objectively. Results of research conducted at the barbershop in Puskesmas II North Purwokerto result of six places in the category of Good Enough with the highest value at the barbershop $F$ with a value of $79 \%$ of the lowest value in the barbershop $D$ at $57 \%$ and the average values in each barbershop is $66 \%$. Conclusions This study is the sanitation situation Barbershop at six places in Puskesmas II North Purwokerto gets categories Pretty Good with value - average $66 \%$.
\end{abstract}

Keywords : sanitation, sanitation public place

\section{PENDAHULUAN}

Berdasarkan PP No. 66 Tahun 2014 dijelaskan bahwa Untuk mencapai tujuan nasional diselenggarakan upaya pembangunan yang berkesinambungan yang merupakan suatu rangkaian pembangunan yang menyeluruh, terarah, dan terpadu, termasuk diantaranya pembangunan kesehatan.

Berdasarkan Laporan Pencapaian tujuan pembangunan Milenium di Indonesia tahun 2010 menunjukkan bahwa, akses sanitasi layak di wilayah perkotaan masih pada angka $69,51 \%$ dari target yang hendak dicapai di 2015 sebesar $76,82 \%$. Sedangkan capaian akses sanitasi layak di wilayah perdesaan sebesar $33.96 \%$ dari target $55.55 \%$ (Bappenas, 2010).
Sarana dan bangunan umum merupakan tempat dan atau alat yang di pergunakan oleh masyarakat umum untuk melakukan kegiatannya, untuk itu perlu dikelola demi kelangsungan kehidupan dan penghidupannya untuk mencapai keadaan sejahtera dari badan, jiwa dan sosial, yang memungkinkan penggunaannya hidup dan bekerja dengan produktif secara sosial ekonomis DIRJEN PPM \& PL Tahun 2002.

Sanitasi adalah suatu cara untuk mencegah berjangkitnya suatu penyakit menular dengan jalan memutuskan mata rantai dari sumber. Sanitasi merupakan usaha kesehatan masyarakat yang menitik beratkan pada penguasaan terhadap berbagai faktor 
lingkungan yang mempengaruhi derajat kesehatan (Arifin, 2009).

Barbershop (Tempat Pangkas Rambut) adalah suatu tempat dimana umum dapat memotong rambutnya dengan dipungut biaya.

Hasil survey pendahuluan awal yang dilakukan maka peneliti memilih Wilayah Puskesmas II Purwokerto Utara sebagai tempat penelitian, Di wilayah tersebut merupakan wilayah dengan jumlah Barbershop (tempat pangkas rambut) terbanyak yaitu 12 tempat.

Tujuan penelitian ini adalah mengetahui keadaan sanitasi Barbershop (Tempat Pangkas Rambut) yang ada di Wilayah Kerja Puskesmas II Purwokerto Utara.

\section{BAHAN DAN CARA}

Jenis penelitian ini adalah deskriptif. Penelitian hanya menggambarkan keadaan sanitasi Barbershop (Tempat PangkasRambut) yang ada di Wilayah Kerja Puskesmas II Purwokerto Utara. Cara pemeriksaan Barbershop (tempat pangkas rambut) meliputi keadaan bangunan, alat dan bahan yang digunakan peralatan dan bahan yang digunakan pada saat mencukur, personal hygiene karyawan, pengendalian vektor, penyehatan udara, pengelolaan sampah Dan juga akan dilakukan pengukuran fisik yang meliputi : suhu, kelembaban, pencahayaan. Pengukuran tersebut akan dilaksanakan selama tiga hari. Untuk pemeriksaan mikrobiologi akan di ambil sampel air bersih yang akan di periksa di laboratorium.

\section{III.HASIL DAN PEMBAHASAN}

\section{Hasil}

Puskesmas II Purwokerto Utara merupakan salah satu puskesmas yang ada di Kecamatan Purwokerto Utara wilayah kerja meliputi 4 Kelurahan yaitu : Kelurahan Sumampir, Kelurahan Grendeng, Kelurahan Karangwangkal, Kelurahan Pabuaran. Luas wilayah Puskesmas II Purwokerto Utara yaitu 460,78 Ha. kelurahan yang paling luas adalah Kelurahan Sumampir yaitu 151,820 Ha, sedangkan Kelurahan yang paling sempit adalah Kelurahan Karangwangkal yaitu $60 \mathrm{Ha}$.

Berdasarkan data dari Kecamatan Purwokerto Utara hasil registrasi penduduk tahun 2014 (data penduduk pertengahan tahun untuk pedoman prestasi hasil kegiatan Puskesmas) yaitu 25.430 jiwa terdiri dari laki-laki12.841 jiwa dan perempuan 12.589 jiwa, tertinggi di Kelurahan Sumampir yaitu 9.496 jiwa dan terendah di Kelurahan Karangwangkal yaitu 2.887 jiwa.

Keadaan Sanitasi bangunan Barbershop (tempat pangkas rambut) yang ada di wilayah kerja Puskesmas II Purwokerto Utara Tahun 2015 berdasarkan penilaian menggunakan checklist dan kuesioner.
Tabel 3.1 : Tabel Keadaan Sanitasi Bangunan Berdasarkan Penilaian Checklist

\begin{tabular}{lccc}
\hline \multirow{2}{*}{ No } & Nama & \multicolumn{2}{c}{ Keadaan Sanitasi } \\
\cline { 3 - 4 } & Barbershop & Jumlah Nilai & Katergori \\
\hline 1. & A & $65 \%$ & Cukup baik \\
2. & B & $58 \%$ & Cukup baik \\
3. & C & $69 \%$ & Cukup baik \\
4. & D & $57 \%$ & Cukup baik \\
5. & E & $68 \%$ & Cukup baik \\
6. & F & $79 \%$ & Cukup baik \\
\hline
\end{tabular}

Tabel 3.2 : Penilaian Sanitasi Barbershop Berdasarkan Penilaian Kuesioner

\begin{tabular}{lccccccc}
\hline \multirow{2}{*}{$\begin{array}{c}\text { No Barber } \\
\text { shop }\end{array}$} & $\mathbf{X}$ & $\mathbf{Y}$ & $\mathbf{Z}$ & $\mathbf{W}$ & Nilai & Katergori \\
\hline 1. & A & $25 \%$ & $83 \%$ & $100 \%$ & $60 \%$ & $62 \%$ & Cukup baik \\
2. & B & $37,5 \%$ & $83 \%$ & $100 \%$ & $83 \%$ & $67 \%$ & Cukup baik \\
3. & C & $37,5 \%$ & $100 \%$ & $66 \%$ & $80 \%$ & $71 \%$ & Cukup baik \\
4. & D & $25 \%$ & $83 \%$ & $66 \%$ & $80 \%$ & $57 \%$ & Cukup baik \\
5. & E & $37,5 \%$ & $83 \%$ & $100 \%$ & $80 \%$ & $61 \%$ & Cukup baik \\
6. & F & $25 \%$ & $80 \%$ & $100 \%$ & $80 \%$ & $71 \%$ & Cukup baik \\
\hline
\end{tabular}

Tabel 3.3 : Hasil Pengukuran Intensitas Cahaya Pada Barbershop pada tanggal 1 - 3 Mei 2015

\begin{tabular}{lcccc}
\hline \multirow{2}{*}{ No } & Nama & \multicolumn{3}{c}{ IntensitasCahaya (Lux) } \\
\cline { 2 - 5 } & Barbershop & 07.00 & 12.00 & 15.00 \\
\hline 1. & $\mathrm{~A}$ & $108 \mathrm{lux}$ & $148 \mathrm{lux}$ & $120 \mathrm{lux}$ \\
2. & $\mathrm{~B}$ & $103 \mathrm{lux}$ & $123 \mathrm{lux}$ & $116 \mathrm{lux}$ \\
3. & $\mathrm{C}$ & $113 \mathrm{lux}$ & $151 \mathrm{lux}$ & $116 \mathrm{lux}$ \\
4. & $\mathrm{D}$ & $101 \mathrm{lux}$ & $106 \mathrm{lux}$ & $101 \mathrm{lux}$ \\
5. & $\mathrm{E}$ & $113 \mathrm{lux}$ & $121 \mathrm{lux}$ & $113 \mathrm{lux}$ \\
6. & $\mathrm{~F}$ & $111 \mathrm{lux}$ & $130 \mathrm{lux}$ & $115 \mathrm{lux}$ \\
\hline \multicolumn{2}{r}{ Rata - rata } & $108 \mathrm{lux}$ & $129 \mathrm{lux}$ & $113 \mathrm{lux}$ \\
\hline
\end{tabular}

Tabel 3.4 : Hasil Pengukuran Kelembaban Pada Barbershop pada tanggal $1-3$ Mei 2015

\begin{tabular}{lcccc}
\hline \multirow{2}{*}{ No } & Nama & \multicolumn{3}{c}{ Kelembaban (\%) } \\
\cline { 2 - 5 } & Barbershop & $\mathbf{0 7 . 0 0}$ & $\mathbf{1 2 . 0 0}$ & $\mathbf{1 5 . 0 0}$ \\
\hline 1. & $\mathrm{~A}$ & $69 \%$ & $67 \%$ & $70 \%$ \\
2. & $\mathrm{~B}$ & $67 \%$ & $70 \%$ & $69 \%$ \\
3. & $\mathrm{C}$ & $66 \%$ & $66 \%$ & $67 \%$ \\
4. & $\mathrm{D}$ & $71 \%$ & $67 \%$ & $74 \%$ \\
5. & $\mathrm{E}$ & $76 \%$ & $70 \%$ & $74 \%$ \\
6. & $\mathrm{~F}$ & $75 \%$ & $66 \%$ & $72 \%$ \\
\hline \multicolumn{2}{l}{ Rata - rata } & $70 \%$ & $67 \%$ & $70 \%$ \\
\hline
\end{tabular}

Tabel 3.5 : Hasil Pengukuran Suhu Ruangan Pada Barbershop pada tanggal 1 - 3 Mei 2015

\begin{tabular}{|c|c|c|c|c|}
\hline \multirow{2}{*}{\multicolumn{2}{|c|}{ No $\begin{array}{c}\text { Nama } \\
\text { Barbershop }\end{array}$}} & \multicolumn{3}{|c|}{ Temperatur Ruangan $\left({ }^{0} \mathrm{C}\right)$} \\
\hline & & 07.00 & \multirow{2}{*}{$\begin{array}{c}12.00 \\
29^{0} \mathrm{C}\end{array}$} & \multirow{2}{*}{$\frac{15.00}{26^{0} \mathrm{C}}$} \\
\hline 1. & A & $27^{0} \mathrm{C}$ & & \\
\hline 2. & B & $28^{0} \mathrm{C}$ & $28^{0} \mathrm{C}$ & $26^{0} \mathrm{C}$ \\
\hline 3. & $\mathrm{C}$ & $27^{0} \mathrm{C}$ & $29^{0} \mathrm{C}$ & $27^{0} \mathrm{C}$ \\
\hline 4. & $\mathrm{D}$ & $30^{\circ} \mathrm{C}$ & $30^{0} \mathrm{C}$ & $28^{0} \mathrm{C}$ \\
\hline 5. & $\mathrm{E}$ & $29^{\circ} \mathrm{C}$ & $30^{\circ} \mathrm{C}$ & $28^{0} \mathrm{C}$ \\
\hline 6. & $\mathrm{~F}$ & $28^{\circ} \mathrm{C}$ & $30^{\circ} \mathrm{C}$ & $29^{\circ} \mathrm{C}$ \\
\hline \multicolumn{2}{|c|}{ Rata - rata } & $28^{0} \mathrm{C}$ & $29^{0} \mathrm{C}$ & $27^{0} \mathrm{C}$ \\
\hline
\end{tabular}




\section{Pembahasan}

Keadaan Sanitasi bangunan Barbershop (tempat pangkas rambut) yang ada di wilayah kerja Puskesmas II Purwokerto Utara Tahun 2015 berdasarkan penilaian menggunakan checklist dan kuesioner.

Hasil penelitian yang dilakukan pada barbershop (tempat pangkas rambut) di wilayah kerja Puskesmas II Purwokerto Utara yang berjumlah enam tempat semua lokasinya cukup strategis, dan mudah di jangkau oleh masyarakat umum. satu tempat A berada di wilayah Sumampir, satu tempat D di jalan kampus, tiga tempat $\mathrm{B}, \mathrm{C}, \mathrm{E}$ di wilayah Karangwangkal, dan satu tempat $\mathrm{F}$ berada di wilayah Pabuaran.

Keadaan lingkungan halamannya cukup bersih, dan tidak ada sampah berserakan, namun pada halaman barbershop (tempat pangkas rambut) masih ditemukan lima tempat A, B, C, D, E yang belum menyediakan tempat pembuangan sampah sementara. Satu tempat F sudah menyediakan tempat sampah di lingkungan halaman. Bagi para pemilik tempat pangkas rambut A, B, C, D, E perlu menyediakannya supaya lingkungan sekitar tetap bersih dan di anjurkan untuk menyediakan tempat sampah yang diberi penutup untuk menghindari adanya sampah potongan rambut yang berceceran sebelum diangkut oleh petugas kebersihan kota untuk selanjutnya di buang ke tempat pembuangan akhir.

Tempat parkir yang disediakan bagi para pengunjung dalam keadaan bersih, tidak ada sampah berserakan, tidak terdapat genangan air, 4 tempat yaitu A, B, C, D lantainya terbuat dari plester dan 2 tempat $\mathrm{E}, \mathrm{F}$ menggunakan paving, kedap air, dan tidak licin. enam tempat tersebut semuanya tidak terdapat pembagian ruang kendaraan roda dua dan roda empat sehingga jika pengunjung yang menggunakan roda empat harus memarkirnya di tepi jalan, serta di tempat parkir tidak di pasang rambu lalu lintas.

Maka tempat parkir pada 6 tempat tersebut masuk dalam kategori cukup karena masih terdapat kekurangan yaitu tidak terdapat pembagian ruang kendaraan roda dua dan roda empat, serta tidak ada rambu lalu lintas di tempat parkir. Bagi para pemilik tempat pangkas rambut sebaiknya menyediakan tempat parkir sesuai dengan jenis kendaraannya dan diberi rambu lalu lintas untuk mengurangi angka kecelakaan.

Keadaan lantai perlu mendapat perhatian karena lantai yang tidak memenuhi persyaratan akan mempengaruhi suasana kerja di dalam ruangan tersebut. Hasil penelitian yang dilakukan pada enam tempat barbershop (tempat pangkas rambut) di dapatkan data 5 tempat pangkas rambut yaitu A, B, C, D, E menggunakan lantai keramik, satu tempat pangkas rambut $\mathrm{F}$ menggunakan lantai tegel. Dari data tersebut dapat di jelaskan bahwa lantai dalam keadaan tidak licin, bersih, tidak lembab dan selalu di jaga kebersihannya. Lantai pada enam barbershop (tempat pangkas rambut) yang ada di Wilayah Kerja Puskesmas II Purwokerto Utara sudah memenuhi syarat dengan ketentuan yang berlaku dengan adanya lantai yang bersih dengan sendirinya akan memberi suasana kerja yang lebih baik. Untuk tempat pangkas rambut yang masih menggunakan tegel sabaiknya menggantinya dengan keramik agar suasana tempat kerja menjadi lebih nyaman dan kelihatan lebih terang.

Keadaan dinding ruangan pada barbershop (tempat pangkas rambut) pada enam tempat semuanya sudah menggunakan tembok permanen dari pasangan bata. Enam tempat tersebut lima tempat diantaranya A, B, C, E, F diantaranya sudah baik karena dindingnya bersih, tidak menyerap air dan di cat dengan warna terang. Ada satu tempat pangkas rambut yaitu pangkas rambut yaitu tempat pangkas rambut $\mathrm{D}$ yang keadaan dindingnya kotor karena warna catnya sudah pudar. Tempat pangkas rambut $\mathrm{D}$ dindingnya perlu dilakukan pembersihan dan pengecetan ulang agar dindingnya terlihat lebih bersih dan rapi. Hasil penelitian pada barbershop (tempat pangkas rambut) terdapat lima tempat yang sudah memenuhi persyaratan dan satu tempat perlu di dibenahi lagi agar suasana lingkungan kerja yang nyaman dan bersih, maka perlu di perhatikan lagi pemelihraan kebersihan dinding secara menyeluruh.

Fungsi ventilasi disini adalah sebagai tempat pertukaran udara keluar dan udara yang masuk. Hasil pengukuran pada enam barbershop (tempat pangkas rambut) tiga tempat pangkas rambut, luas ventilasi belum sesuai dengan persyaratan. Dan dua tempat tidak ada lubang ventilasinya karena menggunakan AC yaitu tempat A dan C. penelitian pada empat tempat yaitu B, D, E, F tersebut belum memenuhi persyaratan karena menurut standar persyaratan yang ada luas ventilasi tetap maupun tidak tetap adalah masing - masing sepuluh persen dari luas lantai. Maka ventilasi yang ada belum memenuhi persyaratan. Untuk menangani hal tersebut maka pemilik barbershop (tempat pangkas rambut) B, D, E, F harus menambah luas ventilasi dan juga dapat di usahakan adanya fan. Agar suasana di tempat kerja menjadi lebih nyaman dan produktifitas kerjapun meningkat.

Fungsi atap disini adalah untuk melindungi tempat atau ruangan dari panas dan hujan, untuk itu hendaknya terbuat dari bahan yang kuat dn tidak mudah bocor, begitu pula dengan langit - langit harus terbuat dari bahan yang kuat, mudah dibersihkan serta di cat dengan warna terang/ putih agar dapat memantulkan cahaya.

Hasil penelitian pada barbershop (tempat pangkas rambut) yang berjumlah enam tempat, satu diantaranya yaitu atapnya dalam keadaan baik namun tidak ada langit - langitnya yaitu tempat pangkas rambut D. Lima tempat yaitu A, B, C, D, E, F atap dan langit - langit dalam keadaan baik dan tidak bocor serta langit - langitnya di cat dengan warna 
terang. Bagi tempat pangkas rambut D yang belum ada langit - langitnya hendaknya di pasang langit langit untuk menghindari kecelakaan di tempat kerja dan suasana tempat kerjapun menjadi nyaman dan bersih.

Pencahayaan adalah jumlah penyinaran pada suatu bidang kerja yang diperlukan untuk melaksanakan kegiatan secara efektif. Pencahayaan yang digunakan pada Barbershop (tempat pangkas rambut) yang ada di Wilayah Kerja Puskesmas II Purwokerto Utara. Hasil penelitian yang dilakukan menggunakan penchayaan gabungan antara alam dan buatan. Hasil pengukuran rata - rata pada pagi hari adalah 111 lux, siang hari 130 lux, dan pada sore hari adalah 115 lux. berdasarkan Keputusan Menteri Kesehatan Republik Indonesia Nomor 1405/MENKES/SK/XI/2002 tentang Persyaratan Kesehatan Lingkungan Kerja Perkantoran dan Industri Tahun 2002 menyebutkan bahwa Intensitas Cahaya di ruang kerja minimal 100 Lux. Maka penchayaan yang digunakan pada berbershop (tempat pangkas rambut) yang ada di wilayah kerja Puskesmas II Purwokerto Utara sudah memenuhi persyaratan. Karena hasil rata - ratanya di atas 100 lux.

Penyehatan udara ruang adalah upaya yang dilakukan agar suhu dan kelembaban di ruang kerja memenuhi persyaratan kesehatan. Kelembaban ruangan hasil pengukuran yang dilakukan pada tiga periode waktu yaitu pagi, siang, dan sore. Tempat pangkas rambut A 69\%, B 71\%, C 69\%, D 73\%, E $75 \%$, dan $\mathrm{F} 73 \%$ Rata - rata pada pagi hari adalah $70 \%$, siang hari adalah $67 \%$ dan pada sore hari adalah 70\%. Menurut Keputusan Menteri Kesehatan Republik Indonesia Nomor 1045/ MENKES/ SK/ XI/ 2002 tentang Persyaratan Kesehatan Lingkungan Kerja Perkantoran dan Industri Tahun 2002 menyebutkan bahwa untuk persyaratan kelembaban pada ruang kerja adalah 40-60 persen. Berdasarkan ketentuan tersebut maka enam barbershop (tempat pangkas rambut) tersebut memenuhi syarat. Bila kelembaban udara pada ruang kerja > $60 \%$ maka perlu menggunakan alat dehumidifier, dan bila kelembaban udara pada ruang kerja $<40 \%$ maka perlu menggunakan humidifier (misalnya: mesin pembentuk aerosol).

Kelembaban dan pencahayaan, suhu ruangan juga dapat mempengaruhi suasana kerja. Suhu di dalam ruangan terlalu tinggi akan membuat suasana menjadi panas sehingga menyebabkan produktivitas akan menurun. Hasil pengukuran yang dilakukan pada tempat pangkas rambut A $27^{\circ} \mathrm{C}, \mathrm{B} 27^{\circ} \mathrm{C}, \mathrm{C} 27^{\circ} \mathrm{C}$, D $29^{\circ} \mathrm{C}$, E $29^{\circ} \mathrm{C}$, dan $\mathrm{F} 29^{\circ} \mathrm{C}$ dengan rata - rata nilai pada siang hari adalah $28^{\circ} \mathrm{C}$, siang hari $29^{\circ} \mathrm{C}$ dan pada sore hari $27^{\circ} \mathrm{C}$. Berdasarkan KEPUTUSAN MENTERI KESEHATAN REPUBLIK INDONESIA Nomor 1045/ MENKES/ SK/ XI/ 2002 tentang Persyaratan Kesehatan Lingkungan Kerja Perkantoran dan Industri Tahun 2002 menyebutkan bahwa untuk persyaratan suhu di dalam ruangan kerja adalah $18^{0}-28^{0}$ C. maka berdasarkan hasil pengukuran tersebut tiga tempat yaitu $\mathrm{A}, \mathrm{B}, \mathrm{C}$ sudah memenuhi syarat sesuai dengan yang ditentukan. Tiga tempat D, E, F belum memenuhi syarat karena suhunya melebihi NAB yang ditentukan untuk itu sebaiknya bagi para pemilik tempat pangkas rambut menambahkan lubang ventilasi ataupun menambahkannya dengan pendingin seperti AC atupun kipas angin.

Fungsi pintu adalah sebagai tempat keluar masuknya orang/ barang serta menjamin keamanan terhadap barang - barang atau peralatan lainnya yang berada di dalam ruangan. Data penelitian pada barbershop (tempat pangkas rambut) semuanya mempunyai pintu, tiga tempat yaitu D, E, F menggunakan pintu yang terbuat dari papan kayu, dan 3 tempat A, B, C menggunakan pintu dari kaca stainlees. Pada saat aktifitas sedang berlangsung pintu juga selalu dalam keadaan terbuka.

Ruang pangkas merupakan ruangan yang digunakan untuk kegiatan memangkas rambut. Hasil penelitian yang dilakukan di dapatkan hasil ke enam tempat pangkas rambut semuanya tidak ada pembagian ruangan antara ruang pangkas ataupun ruang kerja dengan ruang tunggu, ruang pangkas dan ruang tunggu dijadikan dalam satu tempat. Ruang pangkas rambut belum memenuhi persyaratan dan dapat pula mengganggu aktifitas karyawan dalam memangkas rambut. Hendaknya bagi para pemilik tempat pangkas rambut untuk memisahkan antara ruang tunggu dan ruang pangkas tidak dijadikan dalam satu tempat dan ruangan.

Sampah yang umum di terdapat pada pemangkas rambut adalah sampah dari potongan rambut yang tidak mudah membusuk. Berdasarkan hasil penelitian bahwa pada delapan barbershop rata - rata hanya memiliki 1 tempat sampah dan peletakannya pun beragam pada Pangkas Rambut G tempat sampah di letakan di luar ruangan dan tempat sampah tersebut tidak berpenutup, pada pangkas rambut Htempat sampah di letakan di ruang tunggu dan tempat sampahnya berpenutup jumlahnya satu buah, pada tempat pangkas rambut $\mathrm{A}$ juga hanya satu buah tempat sampah berpenutup dan di letakan di dalam ruang pangkas, pada Pangkas Rambut E tidak menggunakan tempat sampah melainkan menggunakan kantong plastik dan kardus bekas untuk menampung potongan rambut, pada pangkas rambut Djuga hanya satu buah tempat sampah yang berpenutup dan di letakan di dalam ruangan, pada pangkas rambut $\mathrm{C}$ juga satu buah tempat sampah berpenutup dan diletakan di dalam ruangan, pada $\mathrm{B}$ juga terdapat satu buah tempat sampah berpenutup dan diletakan di dalam ruangan. Jika di lihat kebutuhan, jumlah dan kualitas maka dapat dikatakan belum memenuhi pesryaratan, karena kantong plastik sebagai tempat pengumpulan sementara juga belum tersedia.

Tempat cuci tangan dan kain pengering sangat dibutuhkan pada barbershop (tempat pangkas 
rambut). Karena di dalam pekerjaan tersebut memerlukan kebersihan tangan. Berdasarkan penelitian yang dilakukan pada delapan barbershop (tempat pangkas rambut) tidak ada satupun yang menyediakan tempat cuci tangan dan kain pengering. Tempat cuci tangan memungkinkan untuk terjangkit penyakit kulit melalui tangan dan peralatan cukup besar. Menghindari hal tersebut maka di usahakan bagi pemilik barbershop (tempat pangkas rambut) untuk menyediakan tempat cuci tangan dan kain pengeringnya serta dilengkapi dengan sabun, hal ini dilakukan untuk meningkatkan derajat kesehatan masyarakat termasuk juga karyawan itu sendiri.

Vektor penyakit adalah binatang yang dapat menjadi perantara penular berbagai penyakit tertentu. Hasil penelitian yang dilakukan pada delapan barbershop (tempat pangkas rambut) hasilnya tidak di temukan binatang tikus dan kecoa. Baiknya pemilik tempat pangkas rambut untuk memperhatikan kondisi lingkungan dan bangunan tempat pangkas tersebut agar tidak menjadi sarang tikus untuk itu hendaknya pemilik tempat pangkas rambut harus memperhatikan kosntruksi bangunan tidak memungkinkan masuk dan berkembang biaknya vektor dan reservoar penyakit ke dalam ruang kerja.

Kualitas air bersih memenuhi syarat kesehatan yang meliputi peryaratan fisika, kimia, mikrobiologi dan radioaktif sesuai dengan peraturan dan perundang - undangan yang berlaku. Hasil pemeriksaan sampel air secara mikrobiologi yang digunakan oleh lima tempat pangkas rambut namun pada saat akan di lakukan pengambilan dua tempat tersebut sedang tutup sehingga tidak memungkinkan untuk di ambilsampel air bersihnya. Tiga tempat pangkas rambut tersebut yaitu A, D, E. Hasil pemeriksaan yang dilakukan oleh Laboratorium Kesehatan Banyumas hasilnya tidak ada yang memenuhi syarat. Syarat air bersih yaitu total E. Coli atau fecal coli sebesar 0, dan Total Bakteri Coliform 0, namun hasil pemeriksaan sampel dari tiga tempat tersebut hasilnya $>240$ E. Coli atau fecal coli, dan total bakteri Coliform $>240$. Hal tersebut dapat dipengaruhi oleh beberapa faktor antara lain air terkontaminasi bahan kimia, air tercemar limbah rumah tangga, perpiaan ataupun tempat penampung air yang tidak pernah di bersihkan. Untuk itu sebaiknya pemilik barbershop (tempat pangkas rambut) sebaiknya mengolah air bersih tersebut sebelum digunakan dengan cara memasak atupun juga dengan cara rutin membersihkan tempat penampungan air sebelum di alirkan ke tempat keramas. Air bersih yang digunakan untuk keperluan di tempat kerja sebaiknya diperoleh dari Perusahaan Air Minum, sumber air tanah dan atau sumber lain yang telah diolah sehingga memenuhi persyaratan kesehatan. Sumber air bersih dan sarana distribusinya harus bebas dari pencemaran fisik, kimia, dan bakteriologis. Dilakukan pengambilan sampel air bersih pada sumber, bak dan penampungan dan pada kran terjauh untuk diperiksakan di laboratorium minimal 2 kali setahun, yaitu musim kemaru dan musim hujan untuk mengetahui kualitas air bersih yang digunakan.

Bahan yang digunakan dalam proses pemangkasan seperti bedak, shampo, wangi wangian dan sabun. Berdasarkan hasil penelitian yang dilakukakn bahan yang digunakan pada barbershop (tempat pangkas rambut) yang ada di wilayah kerja Puskesmas II Purwokerto Utara semuanya dalam keadaan baru, terdaftar pada Dinas Kesehatan serta tidak mengandung bahan berbahaya/ beracun. Sehingga bahan yang di gunakan sesuai dengan persyaratan yang ada dan tidak menjadi masalah.

Peralatan yang digunakan pada barbershop (tempat pangkas rambut) adalah gunting, pisau cukur, sisir kain penutup badan dan handuk kecil. Hasil penelitian yang dilakukan semua jenis peralatan yang di gunakan seperti gunting, sisir, pisau cukur dan kain penutup badan di bersihkan terlebih dahulu sebelum digunakan, untuk handuk setelah digunakan langsung di cuci kembali. Dilakukan untuk menghindari penularan penyakit yang disebabkan oleh peralatan yang tidak bersih. Di anjurkan kepada karyawan pemangkas rambut. Agar mengikuti aturan yang berlaku. Dengan demikian secara tidak langsung sudah meningkatkan derajat kesehatan masyarakat.

Karyawan atau tenaga pemangkas rambut mempunyai peranan yang sangat penting dalam menciptakan lingkungan kerja yang sehat dan bersih. Hasil penelitian yang dilakukan dari enam tempat barbershop (tempat pangkas rambut) semua karyawannya belum memiliki sertifikat kesehatan. Sehingga di anjurkan untuk memiliki sertifikat kesehatan. serta memeriksakan diri secara berkala minimal dalm satu tahu dua kali. untuk menciptakan semua ini perlu adanya kerja sama yang baik antara Puskesmas dan Pemilik Barbershop (tempat pangkas rambut). Hal ini dilakukan untuk mengetahui kesehatan karyawan dan juga untuk meningkatkan produktivitas kerja dan untuk meningkatkan derajat kesehatan masyarakat yang stinggi - tingginya.

\section{IV.KESIMPULAN}

Keadaan sanitasi Barbershop (tempat pangkas rambut) pada enam tempat mendapat kategori cukup baik dengan nilai rata - rata $66 \%$. Ada beberapa hal yang masih perlu untuk di perbaiki lagi dan di tambahkan agar kedepannya menjadi lebih baik lagi.

Keadaan bangunan padaBarbershop (tempat pangkas rambut) pada enam tempat semuanya memenuhi syarat dengan nilai rata - rata 92,5\%.

Hasil pemeriksaan sampel air bersih pada tiga tempat pangkas rambut kamase, jogja barber sumampir, arya barber karangwangkal secara mikrobiologi di Laboratorium hasilnya belum memenuhi syarat karena E. Coli atau fecal coli dan Total Bakteri Coliform hasilnya masih di atas NAB yaitu jumlah per $100 \mathrm{ml}$ sampel adalah 0 . 
Untuk Pengelolaan sampah berdasarkan hasil penelitian 4 tempat yaitu A, B, C, E sudah memenuhi syarat karena sudah menggunakan tempat sampah yang kedap air, berpenutup. 2 tempat D, Fbelum memenuhi syarat karena tempat sampah yang digunakan belum sesuai dengan yang di persyaratkan.

Pengendalian vektor lalat dan tikus berdasarkan hasil penelitian memenuhi syarat dengan kategori cukup baik. nilai rata - ratanya yaitu $61 \%$. Pada saat penelitian dilaksanakan tidak ditemukan vektor tkus maupun kecoa pada tempat pangkas rambut.

Penyehatan udara ruang adalah upaya yang dilakukan agar suhu dan kelembaban di ruang kerja memenuhi persyaratan kesehatan. Berdasarkan hasil pengukuran fisik Kelembaban Udara hasilnya memenuhi syarat karena rata - ratanya adalah $69 \%$ jika hasil tersebut dibandingkan dengan Nilai Ambang Batas Kelembaban Udara pada ruangan adalah 40 - 60\% maka kelembaban udara pada tempat pangkas rambut sudah memenuhi syarat.

\section{DAFTAR PUSTAKA}

DepartemenKesehatan R.I, 2002, PedomanUmum Hygiene Sarana Dan BangunanUmumjakarta: DirektoratJenderal PPM\&PL

2014, No 66 Peraturan Pemerintah Republik Indonesia tentang Kesehatan Lingkungan

2002,No1045/Menkes/SK/XI/20

02 tentang Persyaratan Kesehatan Lingkungan Kerja Perkantoran dan Industri

1999,No829/Menkes/Per/SK/VI

I/1999tentang Persyaratan Kesehatan Perumahan dan Lingkungan Permukiman. Jakarta : Depkes RI
1990,No416/Menkes/Per/IX/1

990 tentang Persyaratan Kualitas Air Bersih. Jakarta : Depkes RI

Hernady, Sujoto, 1993, Buku Pedoman Sanitasi Tempat-tempat Umum. Purwokerto : Akademi Penilik Kesehatan Teknologi Sanitasi.

Mukono HJ, 2000 Prinsip dasar Kesehatan Lingkungan Surabaya : Airlangga University Press, pp 155-157.

Puskesmas II Purwokerto Utara, 2014, Profil Kesehatan Puskesmas II Purwokerto Utara Tahun 2014, Pemerintah Kabupaten Banyumas, Dinas Kesehatan Kabupaten : Banyumas.

Reksosoebroto, Soebagio, 1978, Hygiene dan Sanitasi, Jakarta : Akademi Penilik Kesehatan Sanitasi.

Riyadi Slamet, 1984, Kesehatan Lingkungan Dalam Konteks perkembangan Lingkungan Dewasa ini, Surabaya : Karya Anda

Sumantri Arif, 2010, Kesehatan Lingkungan dan Perspektif Islam, Jakarta:Kencana Media Group.

Suparlan, 1981, Pedoman Pengawasan Sanitasi Tempat-tempat Umum Surabaya: APK-TS.

Tri Cahyono, 2014, Pedoman Penulisan Proposal Penelitian dan Karya Tulis Ilmiah (edisi revision ke enam), Purwokerto : Departemen Kesehatan RI Poltekkes Depkes Semarang Jurusan Kesehatan Lingkungan 